\title{
BUILDING GEOSPATIAL COMPETENCES IN TANZANIAN UNIVERSITIES WITH OPEN SOURCE SOLUTIONS
}

\author{
N. Käyhkö ${ }^{a^{*}}$, C. William ${ }^{\text {b }}$, J. Mayunga $^{\text {c }}$, M.O. Makame ${ }^{\text {d }}$, E. Mauya $^{\mathrm{e}}$, A. Järvi ${ }^{\mathrm{f}}$ \\ ${ }^{a}$ University of Turku (UTU), Department of Geography and Geology, 20014 Turku, Finland - niina.kayhko@utu.fi \\ ${ }^{\mathrm{b}}$ University of Dar es Salaam (UDSM), Department of Geography, Tanzania - willmpc@gmail.com \\ ${ }^{c}$ Ardhi University (ARU), Center for Information and Communication Technology, Tanzania - mayungax@ gmail.com \\ ${ }^{\mathrm{d}}$ State University of Zanzibar (SUZA) Department of Social Sciences, Tanzania - maqam04@ gmail.com \\ e Sokoine University of Agriculture (SUA), College of Forestry, Wildlife and Tourism, Department of Forest Operations Management \\ and Techniques, Tanzania - ernestmauya @gmail.com \\ ${ }^{\mathrm{f}}$ University of Turku (UTU), Department of Future Technologies, 20014 Turku, Finland - antero.jarvi@utu.fi
}

\section{Commission IV, WG IV/4}

KEY WORDS: Geospatial, ICT, GIS, Geography, Institutional Cooperation, Higher Education Institutions, Tanzania

\begin{abstract}
:
The GEO-ICT is an institutional cooperation project aiming at improving the quality and societal relevance of geospatial and ICT research and education at the Universities of Dar es Salaam (UDSM), Ardhi University (ARU), State University of Zanzibar (SUZA) and Sokoine University of Agriculture (SUA). Jointly with the University of Turku (UTU) Finland, the institutions focus on strengthening geospatial and ICT skills of the staff, establishing new curricula, upgrading supportive infrastructures and creating synergetic cooperation modalities with different stakeholders in the society. In this paper we share how our practical experiences of the cooperation, including what is the background for the establishment of institutional cooperation between these universities, how is the project operating in practice, what type of activities and cooperation modalities we do together and how do we think institutional cooperation contributes to the advancement of geospatial expertise in Tanzania and what is the role of open source solutions in this development.
\end{abstract}

\section{INTRODUCTION}

During the last years, diversification and accessibility of geospatial and ICT technologies, open access for various regional and global data repositories and increased public access to webmapping and open source technologies have shifted locationbased (geospatial) solutions to core strategical role all over the world. The current estimates show that Geospatial business, grows globally at around 13\% annual rate and location-based solutions are embedding into most of the industry segments (Geospatial Media and Communications, 2018).

Much of this growth is related to societies becoming agile and responsive due to fluent access to reliable and up-to-date location-based digital information through technologies such as Global Positioning Systems (GPS), cloud-based satellite image archives, open-source software, telecommunication and mobile technology. At the same time, it is well known that strong institutions play a crucial role in the development and uptake of geospatial solutions in the society (Geospatial Media and Communications, 2018). Geospatial information has become an enabler for many mass-market applications, and through public participation consumers have become not only flexible and adaptive users of geospatial information but also producers of new information (crowdsourcing, Open Street Map, social media). Increasingly, the business is moving from conventional expert data production to data generation by the public, development of various consumer services based on accessible

\footnotetext{
Corresponding author
}

data repositories and integrating GIS into any field of business, where location matters (geospatial business intelligence).

Simultaneously, rapid economic growth, rising middle class, and the extensive distribution of and access to mobile technologies have made developing countries in Sub-Saharan Africa desirable new markets for high technology geospatial businesses (African Development Bank, 2015:19). Tanzania is currently one of the most rapidly growing nations in population and economy. The population is over 52 million, and the annual economic growth has been approximately 7\% (World Bank, 2016). Tanzania is a country of declining poverty lines and income disparity with high development potential economically and socially. In 2015, Tanzania was ranked to be the fifth fastest growing economy in the world. Despite of the economic growth, a large number of location-based problems in the society remain unsolved, for example in the sector of socio-economic development, urban development, environment, natural resources, forests and marine resources, climate change, logistics, and land allocation and planning. This has created increased need for geospatial and ICT expertise in Tanzania.

Tanzanian higher education institutions' (HEIs) attention is currently drawn to issues of quality and relevance of geospatial and ICT research and education, since societal needs call for their urgent attention. Despite the fact that geospatial and ICT expertise is constantly increasing in the universities, and in the society in general, universities still have lack of skilled staff, upto-date research environments and institutional modalities for 
stakeholder cooperation. Thus, HEIs are unable to transform geospatial and ICT skills fully into tangible benefits for their students and for the society at large. As skills are concentrated too much in the hands of a few individuals, rather than institutions as a whole, international funding opportunities are missed and large tenders, for example, are won by international groups rather than by local institutions. Additionally, geospatial and ICT competences do not yet embrace sustainable institutional and inter-institutional capacities and many opportunities raising from the synergies and cooperation are underused. Many experts act on their own in the private sector rather than as strong team and networks of expert institutions. Therefore, Tanzanian universities, who are currently interested in putting their strategical and practical efforts into improvement of these skills are in need of partnerships, which can help them to steer the expertise into sustainable trajectories.

In this paper we share how our experiences of the cooperation between the University of Turku, Finland, and four Tanzanian universities on the institutional geospatial and ICT capacity building. We share our cooperation modalities and experiences and views of how institutional cooperation contributes to the advancement of geospatial expertise in Tanzania and what is the role of open source solutions in this development.

\section{INSTITUTIONAL COOPERATION AS A FORM OF COMPETENCE DEVELOPMENT}

\subsection{Long-term cooperation between UDSM and UTU}

Universities of Dar es Salaam and Turku have had research, education and development cooperation in Tanzania in the sector of geospatial applications and Geography since 2003. The first ten years of the cooperation was involved around shared research and training activities in projects in Zanzibar and mainland Tanzania (tanzania.utu.fi). These research projects allowed individual teachers and students from UDSM and UTU visit each other, learn methodological skills in GIS and Geography and obtain practical experiences on how to use geospatial data and methods in mapping natural resources, forests and landscapes, to model landscape changes and their impacts on local livelihoods and to use participatory GIS methods in land use and forest planning. This cooperation has sprouted several academic theses and scientific articles over the years (eg. Makandi, 2008, Käyhkö et al., 2011, Fagerholm et al., 2012, Eilola et al., 2014, Zahor, 2014, Kukkonen \& Käyhkö, 2014, Khamis et al., 2017).

In 2008, first institutional steps in the cooperation were taken, when teacher-student mobility started and MOU between the two universities was signed. These NSS mobility projects (NorthSouth-South) run between UTU and several African universities, including UDSM until 2015, when the funding instrument was terminated by the Ministry for Foreign Affairs (MFA) of Finland.

In 2013, UDSM and UTU applied for an institutional cooperation funding for the development of GIS teaching at UDSM. Project "HEI-GIS capacities at UDSM Geography" run from 2013 to 2015, and it had several tangible benefits to the Department of Geography of the University of Dar es Salaam. Firstly, in late 2015 Department of Geography launched the first MSc in GIS degree in Tanzania, and that fulfilled a long desire to have a formalized post-graduate level possibility to train future GIS experts within Geography. Secondly at the end of the project UDSM Geography staff had 12 GIS experts compared to 3 before the project started. Most of the training in the project was focused around using free data and free software (Quantum GIS) in order to create basis for more sustainable and cost-efficient maintenance of geospatial competences. Thirdly, compared to previously theoretical and demonstrative GIS courses, a GIS teaching laboratory with 22 computers and GIS open source software was in place, against complete absence of practical GIS teaching prior to the HEI-GIS project. In 2016, after the completion of the HEI-GIS project and in front of another funding possibility from the Higher Education Institutional Cooperation Instrument (HEI instrument of the MFA of Finland), we decided to extend the cooperation into several universities in Tanzania and seek for meta-level change. Therefore current cooperation aims to transform some of the best practices from HEI-GIS project to a larger beneficiary realm, and bring in new elements from the sector of ICT and entrepreneurship capacities to link the academic developments more strongly with societal possibilities and ICT in general.

\subsection{GEO-ICT Project}

Geospatial and ICT capacities in Tanzanian Higher Education Institutions (GEO-ICT, 2017-2020, http://www.geoict.org) was established on the foundations of the long-term cooperation. In the GEO-ICT project, we focus on geospatial and ICT competence development at the University of Dar es Salaam (UDSM), Ardhi University (ARU), State University of Zanzibar (SUZA) and Sokoine University of Agriculture (SUA). (http://www.cimo.fi/programmes/hei_ici_index/programmes/hei ici/projects/geo-ict). More explicitly we aim at improving the quality of higher education and research environment, including improving the skills and pedagogical competence of staff, renewing teaching structures and materials and upgrading research and education environment with key infrastructures (Figure 1). Furthermore, we will work on strengthening the role and relevance of geospatial and ICT in the development of the society, including improving stakeholder networks and collaboration modalities and introducing universities with relevant and catalysing role in the innovation realization and entrepreneurship support for the emerging geospatial/ICT business sector in Tanzania.

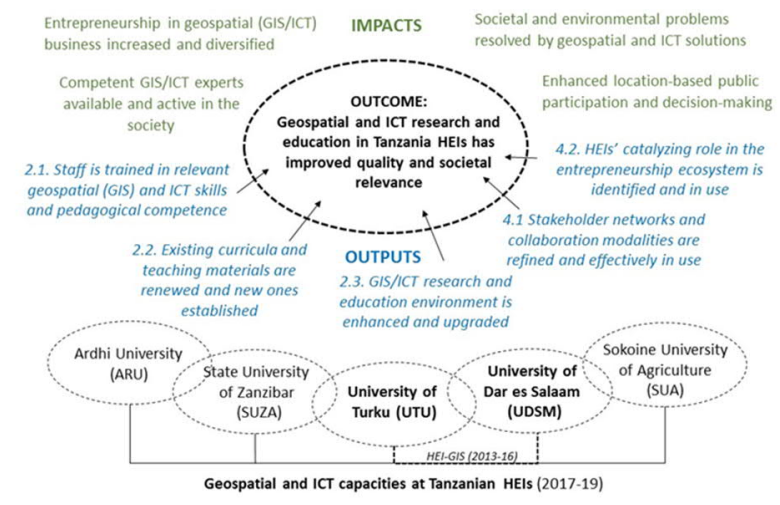

Figure 1. The overall structure and objectives (outputs) of the GEO-ICT project aim to improve the quality and societal relevance of geospatial-ICT research and education.

If we reach the desired objectives of the project, the quality and societal relevance of geospatial and ICT research and education in four Tanzanian universities has improved (Project outcome), and they have increased synergy, interdependency and well performing stakeholder collaboration in GEO-ICT expertise and its applications in the society. The project thrives from strong and living stakeholder collaboration and accessibility of digital data 
and software without financial burdens, and we are seeking for a good and constructive dialogue with different government, civil and private sector actors throughout the project in order to steer the development of geospatial expertise towards practical needs in the society.

\subsection{Open source solutions as one of the key cross-cutting themes of the cooperation}

In the process of planning and initializing the project, we identified several specific competence development needs for Tanzanian universities' geospatial and ICT research and education. We also wanted to steer the work around open source solutions, including using free-access data, web resources, software and promote application sector development around OS-solutions in general. We formulated the explicit development needs as follows:

- Due to theoretical emphasis of education, all HEIs need more practical training and coaching contents into their curricula and courses, and also genuine win-win partnerships with stakeholders, so that students can tackle with real world location-related problems.

- Current research and education environment in many of the HEIs is not up-to-date and lacks critical infrastructures (hardware, software, internet, power supply, materials). We aim for cost-efficient and open-source solutions, also anticipating that mobile solutions are more used options of the future and that investments to infrastructure in the long run may also come from the cooperation partners.

- HEI experts need training especially with recently emerged geospatial/ICT technologies and their uses in research and education (e.g. open source solutions, mobile technologies, crowdsourcing and participatory GIS). There is a shortage of entrepreneurship training in the interface of GIS/ICT in all HEIs, and this is a novel education and research development sector globally.

- Cooperation roles, modalities, synergies and values between HEIs have not yet been fully recognized, and those which exist, focus only on limited application fields. Therefore, a lot of the HEIs' research expertise in different societal and environmental fields is not utilized in practice. These type of deficiencies are typical when there are signs of emerging business ecosystems in the country, but no fully understood value chain identified or realized yet. This is not a problem of only HEIs, but all the actors in the geospatial ecosystem. Therefore, successful solutions lie in the simultaneous improvements of HEI capacities and their stakeholder networks.

- $\quad$ Furthermore, there are limited entrepreneurship capacities and innovation development in HEIs in the sector of GIS/ICT and various applications, but there are plenty of needs in the society. Working in the interface of geospatial/ICT sectors requires practical, beneficiaryoriented skills and confidence to succeed. It requires competence development at the level of the institutions and individuals simultaneously, and in synergy with key actors in the society.

\section{COOPERATION MODALITIES IN GEO-ICT}

\subsection{Strategical level planning}

The GEO-ICT project is coordinated, planned and steered by a team of four experts from each university. The experts are senior level staff members, whose institutional position and expertise allows long-term planning of the project activities and engagement of their home department's staff into an institutional level development work. Strategical level planning is related to how universities, involved disciplines and experts foresee directions of their competence development in relation to the advancements in the geospatial and ICT sector in Tanzania, in East Africa and globally. Strategical discussions are made whenever the whole project team meets, when different stakeholder events take place and also constantly in smaller teams, whenever there is a possibility. Since all the project partners have also other cooperation partners, the idea is to promote long-term strategical level planning now only around the GEO-ICT project, but around the theme and competences in general at the universities.

The key objective of the strategical level planning at the level of all the project partners is to brainstorm the development objectives of the project against envisioned future developments in geospatial and ICT sector. This type of visionary and ideasharing cooperation is not aim in binding and freezing the project development work in practice, but its role is to provide food for though and motivation for long-term development work, which stretches beyond the project time-frame and scope (Figure 2). It also allows partners to discuss how their own universities' roles may coincide or differ in terms of the other partners' visions and how to identify complementary roles for the development work in Tanzania.

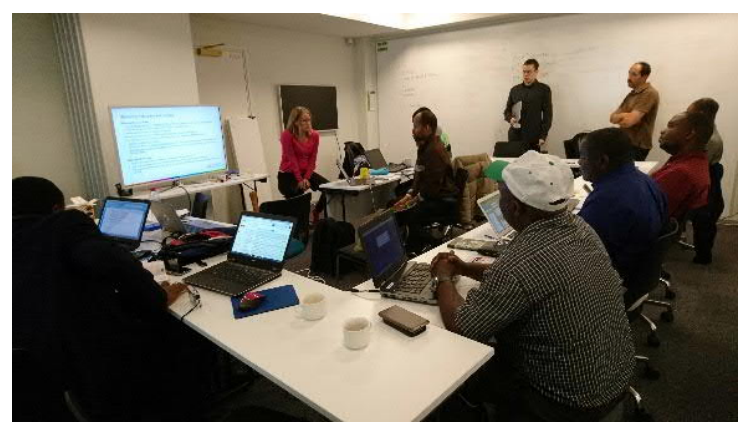

Figure 2. Discussing about strategical choices of the project in Turku between all the universities (September 2017).

The role of the Finnish partner is not only to bring practical experiences from Europe and from Finland into the discussions, but also think with the whole team how geospatial and ICT capacities could be jointly developed. For example in September 2017, coordinators and co-coordinators from all four universities travelled over to UTU for two weeks. The focus of the visit was not only on explicit geospatial or ICT skills training, but also to make strategical planning of the project though sharing experiences and visions (Figure 2). On top of envisioning the development as a group effort between all the universities, strategical discussions have also been useful within disciplinerelated teams as well as between and within each university team (Figure 3).

It has been very clear how strategically important geospatial experts have seen the open source solutions, especially when thinking of linking ICT and geospatial competences into software application developments and services in the society. This has been one of the key discussion topics stretching from the contents and themes of the skills development also to how to use the limited funds for improving infrastructures at the universities (hardware, software, networks). 


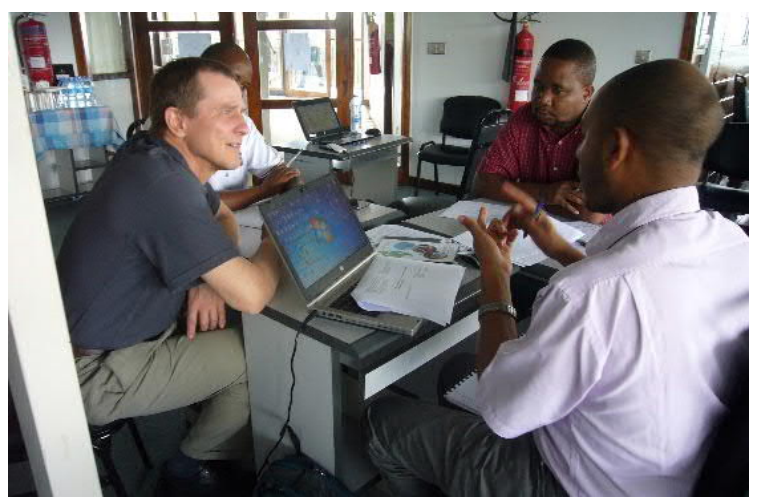

Figure 3. Planning competence development priorities for Sokoine University of Agriculture (SUA) in Dar es Salaam (May 2017).

\subsection{Curricula development work}

One of the most substantial institutional competence development efforts in the universities is the revision of existing and development of new curricula. It requires team work and commitment of the whole department, support of the institutions and also engagement of the key beneficiaries.

In the GEO-ICT project, we have chosen several existing geospatial curricula (at BSc, BA, MSc levels) as targets of improvements, as well as decided to establish 4 to 5 new curricula during the course of the project. This does not mean, however, that the contents of the programmes are sole efforts of the project, but rather that the project provides fruitful environment for curricula development and review work at the participating institutions and contributions from the whole team can be taken into account. This means suitable timing, co-creative atmosphere, and strategical support to take the development work from the initial stages to the level of implementation. The funds of the project facilitate team meetings, UTU team feedback and planning support and learning of some new skills, just to mention a few (Figure 4). But the actual contents and objectives of the programmes are choices of the institutions, departments and experts involved.

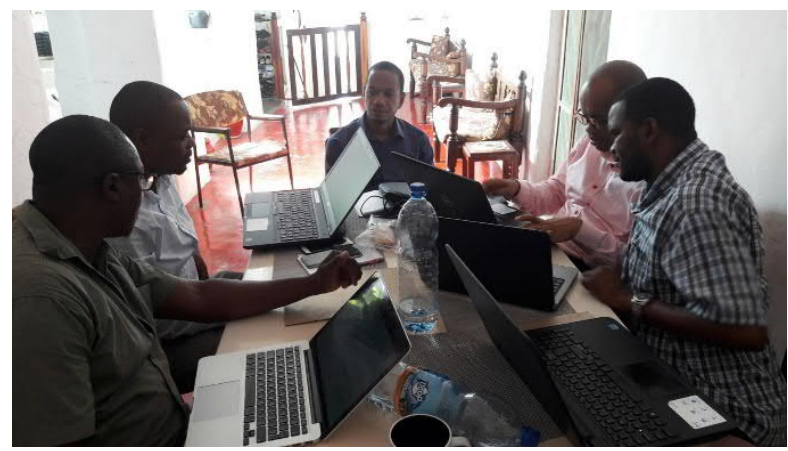

Figure 4. Curricula development meeting of SUZA team with UTU experts in Zanzibar (January 2018).

One of the characteristic elements of the project is that we aim to identify novel combinations in the contents of the curricula and courses between traditional geospatial disciplines (such as Geography, Geoinformatics) with more generic ICT. This means that curricula in ICT, for example, will have selected skills development contents related to geospatial data management, visualization and emerging businesses built on OS solutions, for example. We also aim at establishing stronger entrepreneurship elements into all the reviewed and established programmes.

\subsection{Skills training}

The GEO-ICT follows up a 'training of the trainers' -approach, where we focus on skills development of the staff members, who then are expected to transfer their skills via regular teaching to their students (curricula courses) and via course services (short courses) to their stakeholders. Since the range of courses, which can be financially supported by the project are limited, the experts make choices of the skills training topics once a year. By April 2018, the project had organised three intensive skills training sessions in Tanzania with participants from all four universities. All the trainings have been 4-5 days, with some preparatory and follow-up work required from the participants and departments.

In November 2017, Introduction to Geoinformatics -training was held at ARU for all partner university researchers and teachers (16 participants). The training was targeted to staff members who have limited knowledge in working with geospatial data and using GIS software, such as staff members from ICT (Figure 5). The training introduced participants to geographical information systems (QGIS), spatial data and uses of GIS in the society including geospatial data production and management, basic spatial analyses and data interpretation, as well as introduction to remote sensing data and web applications, cartographic communication and visualization. The course included also a participation to GIS Day Tanzania on November $15^{\text {th }}$ at ARU with a learning task (see section 3.5 for details of the events).

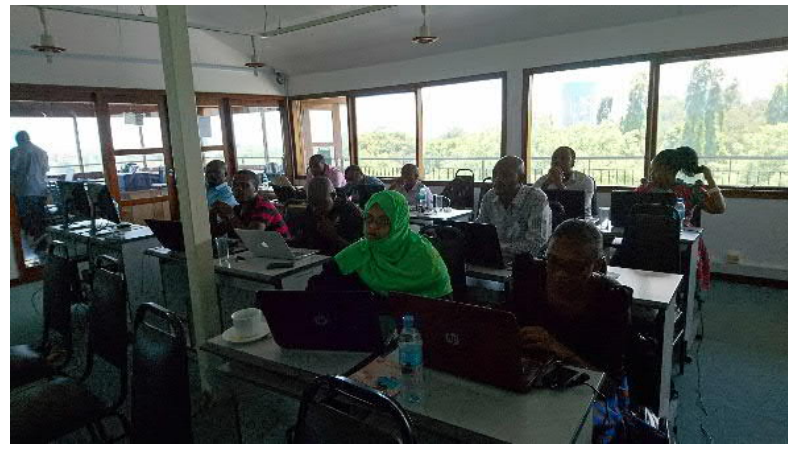

Figure 5. Basic GIS training at Ardhi University for UDSM, ARU, SUA and SUZA teachers and researcher using QGIS (November 2017).

In March 2018, a Pedagogical Training was held at UDSM for 16 GIS teachers, who all improved pedagogical approach of their selected courses under a guidance of a teaching expert from UTU. The course aimed at supporting teachers to apply cognitive taxonomy (Bloom's taxonomy revised by Krathwohl and Anderson, 2001) and different knowledge dimensions in designing appropriate learning outcomes and teaching methods for a GIS related course. The course also introduced participants with different criteria-based evaluation methods and how to use them, as well as what type feedback mechanisms could be applied in the courses.

In March 2018, another training was held on Remote sensing with Open Source Tools at SUA in Morogoro (12 participants). The course focused on the use of optical remote sensing data in different open source software and online apps. Specifically, the course introduced the participants to Open Foris -software suite (www.openforis.org), which is developed for forestry and land 
use assessments by the UN Food and Agricultural Organization (FAO). During the training, Open Foris Collect was used for survey creation and Open Foris Collect Earth for data collection using high-resolution satellite imagery from Google and Bing repositories. In addition, the management, processing and analysis of remote sensing data in QGIS software and online platform Google Earth Engine was practiced.

\subsection{Co-creative participatory workshops and events}

One of the strategies of GEO-ICT is to link university skills development into real world cases through participatory approaches, which engage academic and practitioners to joint innovation and business brainstorming work. Since 2016 we have jointly organized different type of co-creative workshops and events in Tanzania, which have been allowing participants to brainstorm geospatial business and problem-solving solutions around real world needs.

For example in April 2016, we organized two geospatial business hackathons, which aimed at discovering feasible business solutions around location-related problems in Tanzania. The hackathon in Dar focused on urban development challenges and the one in Zanzibar on tourism (Figure 6).

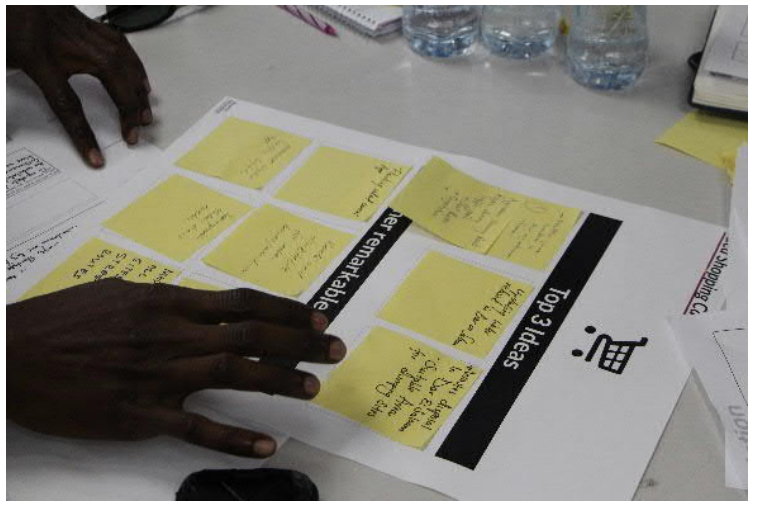

Figure 6. Geospatial Business Hackathon was organised in at Buni Hub in order to develop possible business solutions around location-related urban problems, such as delivery services (April 2016).

In May 2017, we organised another 2-day business innovation event at CoICT (UDSM), but this time jointly with Nokia Smart City team (https://networks.nokia.com/smart-city). On the first day, Tanzanian master level students of ICT, business, planning and GIS were introduced with the aspects of sustainable city development and enabling smart city technologies, and cases of recent development of smart solutions for urban environments. Then students worked as six teams to identify problems and refine selected solutions for problems related to the topic (Figure 7). On the second day these solution were presented to an audience consisting of high profile stakeholders representing Tanzanian government and city municipals, local and multinational companies and universities. The second day audience was invited to discuss aspects of enabling and empowering the development and business creation of such innovations that resulted in the first phase workshop.

In the GEO-ICT project, our aim is to refine these innovation event experiences into feasible competence development solutions for the universities. For that, we organised a two day user-centered innovation workshop in Buni Hub in November 2017, where the purpose of the workshop was to experiment how user-centred design and prototyping methods can be used to bring local contextual knowledge in the innovation process solving problems in urban environment. The innovation workshop feedback from the participants was encouraging for the continuation and development of similar events to as a learning tool in the geospatial and ICT competence development.

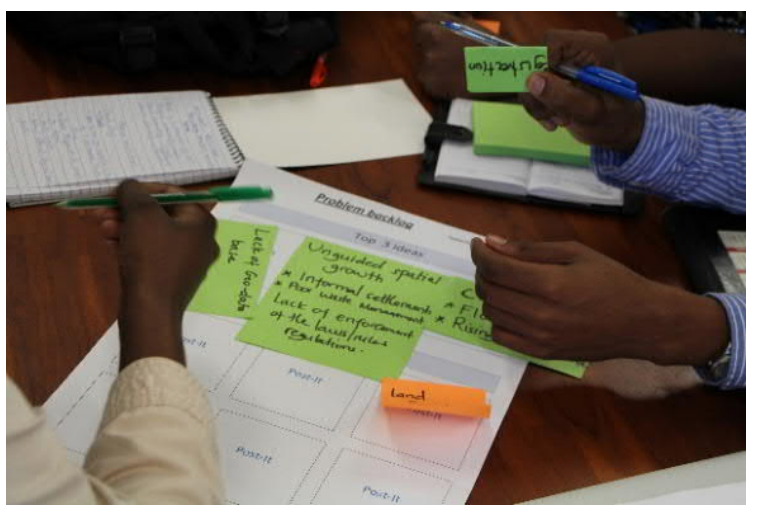

Figure 7. Two-phased innovation workshop aimed at training participants with location-based smart city solutions in Tanzania (May 2017).

\subsection{Dissemination events}

During the first year of the project, the team has been visible in four events in Tanzania and Finland. Firstly, we had the project kick-off stakeholder event in Tanzania in May, where we advertised the project and invited stakeholders for shared development work and discussion about the future geospatial and ICT development needs (Figure 8).

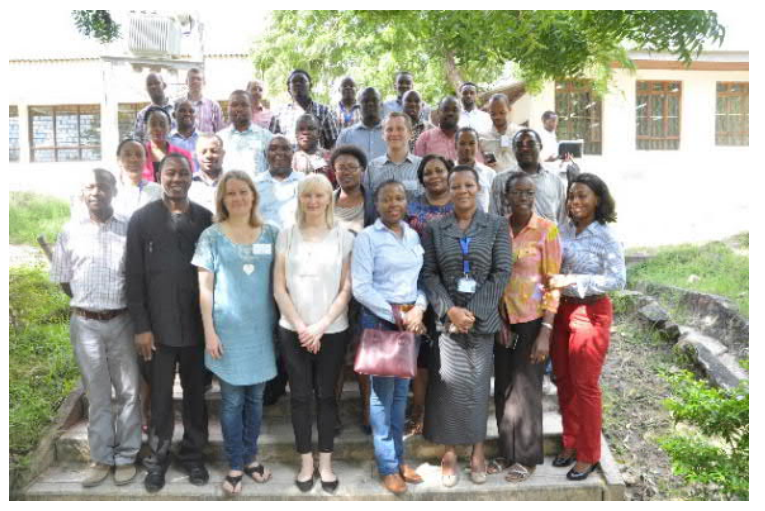

Figure 8. GEO-ICT project kick-off seminar was organised at Ardhi University to disseminate knowledge and invite stakeholder for cooperation in geospatial and ICT competence development issues in Tanzania (May 2017).

When the coordinators were visiting Finland in September 2017, we held "Tanzania Geospatial-ICT research, education and networking day" in Turku to enable Tanzanian and Finnish geospatial experts meet and link their interests. The aim of the event was to bring together Finnish and Tanzanian actors working and interested in the geospatial and ICT sectors of Tanzania and talk about Tanzanian business opportunities. The event was organized in synergy with other projects ongoing in Tanzania, and matching with the Zanzibar government authorities' professional visit to Finland (see more about the projects at tanzania.utu.fi). The event, which was held at Boost Turku (https://boostturku.com) gathered around 50 participants from Finland and Tanzania. The afternoon of the event was reserved 
for a workshops covering topics of business culture in Tanzania, universities as enablers of innovation development and publicprivate partnerships in the fields of geospatial technologies and ICT.

In October 2018, we took part in the ESRI East Africa GIS conference in Tanzania, where we advertised our Tanzania Geospatial Survey 2017. The Geospatial Survey was launched in mid-2017 (until January 2018) as a shared effort of the GEO-ICT and GESEC -projects (see tanzania.utu.fi) in order to gather and share information of the geospatial sector development in Tanzania, as identified by those who are acting in the sector. Preliminary results of the survey were shared at the conference and stakeholders were further invited to answer the survey.

In November 2017, our team was actively taking part in the organising of the Tanzania GIS Day, a tradition, which we jointly started in 2014, when the HEI-GIS project was ongoing. This time the event was held on November $15^{\text {th }}$ at the campus of Ardhi University with around 100 participants, exhibitions and one presentation session (Figure 9).

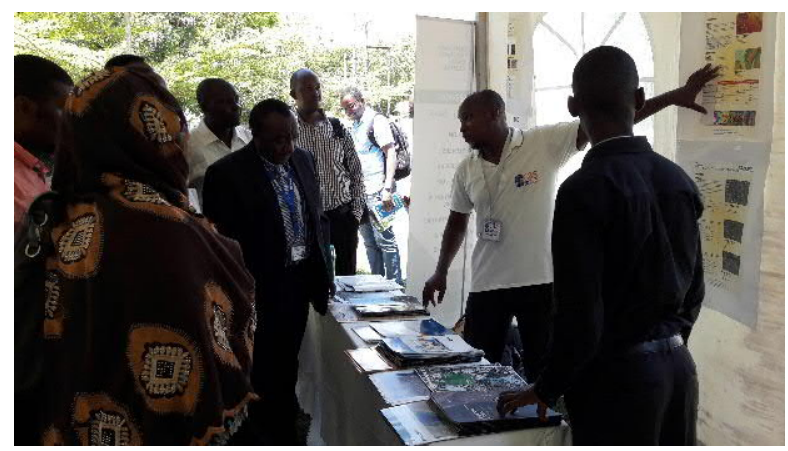

Figure 9. In the GIS Day, geospatial experts, companies and institutions were presenting their ongoing activities and projects in Tanzania (November 2017).

\subsection{Informal team-building events}

One of the rewarding elements of institutional projects is that participants come to know each other as colleagues and as friends over time. Commitment and motivation in long-term projects can be promoted via shared informal events and trips, which we have been doing many over the years of the cooperation. Informal team-building allow professional and personal interests related to the theme of the project to be discussed without schedules and pre-defined structures (Figure 10).

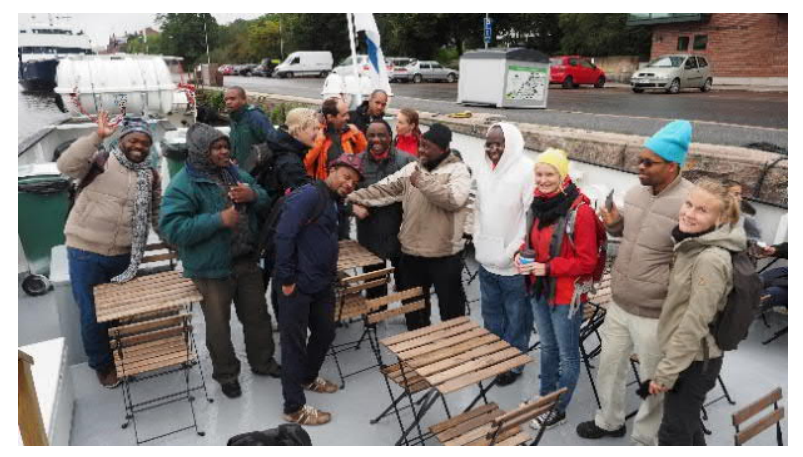

Figure 10. GEO-ICT team visiting the Archipelago Research Institute of the University of Turku in September 2017 with a research vessel (September 2017).
Although informal team-building events are not usually stated as official modalities of institutional cooperation, they hold an important role of the commitment of the key individuals to longterm cooperation with one another.

\section{DISCUSSION}

GEO-ICT project is an ongoing institutional cooperation between five universities. In this paper we have explained what has been the background motivation and previous cooperation behind the project, and we have shared our forms of cooperation and practical experiences from the joint work for far. The impacts and consequences of the project can only be estimated when the project is finished and impacts of improved institutional competences can be practically seen in the society. This may take years, but institutional cooperation is a long-term strategy for competence development, without immediate profits. It differs substantially from many other type of projects, which seek for immediate impacts.

The role of the open-source solutions in the advancement of geospatial and ICT competences at the institutional level are substantial, since they enable much broader scope for the overall competence development work and facilitate practical cooperation between disciplines of ICT and geospatial sciences. This cooperation exposure has been very much needed, since ICT and GIS have not had that strong co-existence at the level of disciplines, programmes and courses, let alone research. This is not only a challenge in Tanzania, but recognized surely by all of us who operate in these fields of expertise.

In the sector of GIS, most of the institutions and experts have had long history of relying on proprietary software solutions and still have, since they are so widely used in the society in the traditional sectors of GIS. Although it is important that universities educate experts, who are skilled with wide range of technologies used in the society, this dependency has lowered the pace at the universities of adopting open source solutions in research and training structures. However, the momentum for supporting OS related skills development at the universities is at hand now, since geospatial technologies have become embedded solutions to most of the ICT applications in the society. And this set-up will offer universities a much wider development opportunity than what GIS traditionally has been able to offer. The momentum calls for institutional, both strategical and practical actions, and strong co-creative partnerships, also with the private sector. The private sector development in the geospatial-ICT sector is urgently needed in countries like Tanzania, so that citizens and authorities can catch up with the practical possibilities that mobile technologies, improved access to the internet and large data repositories may offer for the future.

Over the last years Tanzania has become exposed to very promising practical examples of how OS technologies can be used for solving societal problems and how citizens can also be involved into such developments. For example Ramani Huria (http://ramanihuria.org/), which is a community-mapping initiative for improving flood resilience in Tanzania, has impacted hundreds of university students and community members in Dar es Salaam with OS mapping and planning possibilities. When universities, government institutions, voluntary organizations, private sector and larger public start developing practical solutions jointly to current societal problems, the relevance of developing institutional geospatial and ICT expertise in Tanzania becomes concretely understood by the politicians and decision-makers. This will be the key enabler 
of larger societal benefits from geospatial-ICT expertise in Tanzania.

\section{ACKNOWLEDGEMENTS}

We would like to thank the whole GEO-ICT project team for commitment and enthusiasm towards development of geospatial and ICT capacities in Tanzania and in Finland. We would also like to express our sincere gratitude to our cooperation partners from the government, private, NGO and donor sectors, who have been eager to advance geospatial development in Tanzania. We have had a luxury possibility to link GEO-ICT with our other research and education activities in Tanzania (GESEC, SUSLAND, ZAN-SDI -projects) and these synergies have been invaluable. We have also had a very good opportunity to cooperate with geospatial and ICT capacity building efforts of the World Bank and Twente University, and we are looking forward to advancing those synergies also in the future.

The GEO-ICT project (2017-2020) is one of the projects funded by the Higher-Education Cooperation Instrument (HEI-ICI) of the Government of Finland. Finland's Ministry for Foreign Affairs provides funding for the HEI-ICI programme through its development cooperation funds and Finnish National Agency for Education (EDUFI) administrates the programme. The Higher Education Institutions Institutional Cooperation Instrument (HEI-ICI) supports cooperation projects between Finnish and developing country universities (HEI-ICI Programme Document 2016-2018). The projects enable subject-specific, methodological, educational and administrative capacity building. Support for education in developing countries helps to promote skills development, establish a well-functioning, efficient and equal society, encourage entrepreneurship, drive sustainable development and reduce poverty. However, without the funding and commitment of all the participating institutions in Tanzania and Finland, HEI-ICI instrument would not work.

\section{REFERENCES}

African Development Bank, 2015. African Economic Outlook Report 2015: Regional Development and Spatial Inclusion. OECD Publishing, Paris.

Anderson, L. W., and Krathwohl, D. R., 2001. A taxonomy for learning, teaching, and assessing: A revision of Bloom's taxonomy of educational objectives. New York, Longman.

Fagerholm, N., Käyhkö, N., Ndumbaro, F., and Khamis, M., 2012. Community stakeholders' knowledge in landscape assessments - Mapping indicators for landscape services. Ecological Indicators, 18, pp. 421-433.

Eilola, S., Fagerholm, N., Mäki, S., Khamis, M., and Käyhkö, N., 2015. Realization of participation and spatiality in participatory forest management-a policy-practice analysis from Zanzibar, Tanzania. Journal of Environmental Planning and Management, 58, pp. 1242-1269.

Geospatial Media and Communications, 2018. GEOBUIZ, Geospatial Industry Outlook and Readiness Index, 2018 edition. $116 \mathrm{p}$.

Khamis, Z., Kalliola, R., and Käyhkö, N. 2017. Geographical characterization of the Zanzibar Coastal Zone and its management perspectives. Ocean and Coastal Management, 149, pp. 116-134.
Kukkonen, M., and Käyhkö, N., 2014. Spatio-temporal analysis of forest changes in contrasting land use regimes of Zanzibar, Tanzania. Journal of Applied Geography, 55, pp. 193-202.

Käyhkö, N., Fagerholm, N., Asseid B.S., and Mzee, A.J., 2011. Dynamic land use and land cover changes and their effect on forest resources in a coastal village of Matemwe, Zanzibar, Tanzania. Land Use Policy, 28, pp. 26-37.

Makandi, H., 2008. Mapping cropland preferences of the village communities of Unguja, Zanzibar. MSc thesis. 109 p. Department of Geography, University of Turku.

Zahor, K.Z., 2014. Determinants of forest change and their implication on the people's livelihood in Ngezi area, Micheweni District, Pemba. Doctoral Thesis. Department of Geography, University of Dar es Salaam.

World Bank, 2016. Global Economic Prospects, January 2016: Spillovers amid Weak Growth. World Bank, Washington, DC. 